\title{
Gilles de la Tourette's syndrome in a patient with $47(X X X)$ syndrome: a case report
}

\author{
Matteo Chiappedi", Silvia de Vincenzi, Roberta Dolci, Sara De Luca and Maurizio Bejor
}

\begin{abstract}
Introduction: To the best of our knowledge, this is the first report of a comorbidity between Gilles de la Tourette's syndrome and 47 (XXX) syndrome. The clinical picture of Gilles de la Tourette's Syndrome is well described, while 47 (XXX) syndrome is much more rare and has a broader spectrum of possible phenotypic presentations.

Case presentation: An Italian Caucasian girl was referred th the age of 11 to our Rehabilitation Center for anxiety and learning difficulties. The girl had already been diagnosed as having $47(X X X)$ syndrome; she had some rather typical features of the chromosomal abnormality, but she also showed a high level of anxiety and the presence of motor and vocal tics. When an accurate history was taken, a diagnosis of Gilles de la Tourette's Syndrome

emerged.

Conclusions: The possible interaction between peculiar features of these two syndromes in terms of neuropsychological and affective functioning is both interesting for the specific case and to hypothesize models of rehabilitation for patients with one or both syndromes. Executive functions are specifically reduced in both syndromes, therefore it might be hard to discriminate the contribution of each one to the general impairment; the same applies to anxiety. Moreover, mental retardation (with a significantly lower verbal cognitive functioning) poses relevant problems when suggesting cognitive behavioral or psychoeducational rehabilitative approaches.
\end{abstract}

\section{Introduction}

$47(\mathrm{XXX})$ syndrome, also known as triple $\mathrm{X}$ syndrome, was first described in 1959 by Jacobs and coworkers in a woman with ovarian failure [1]. The 47(XXX) karyotype has a frequency of one in 1000 female newborns, but this syndrome is not usually suspected at birth or childhood and is often diagnosed incidentally with prenatal diagnosis or following medical testing for infertility. Diagnosis is confirmed by karyotype analysis and the most common cause is lack of disjunction during maternal meiosis [2]. Patients with 47(XXX) syndrome do not usually present with major malformations, but rather subtle and highly variable clinical features such as high stature, poor motor coordination, language delay, and learning disabilities (often mild) [3]. In some cases patients may present some behavioral problems, such as hyperactivity, poor social interaction, depressive traits or mild depression: even though these psychopathological aspects seem to become less relevant once they leave school, there is an increase in prevalence of psychotic

\footnotetext{
* Correspondence: mchiappedi@dongnocchi.it

Don C Gnocchi Foundation, Piazzale Morandi 6, 2012 Milan, Italy
}

disorders in these patients during adulthood [4]. The intelligence quotient (IQ) of patients with $47(\mathrm{XXX})$ is thought to be on average 20 points lower than controls, with a significant discrepancy between the performance IQ and the verbal IQ (the latter being usually lower). As already mentioned, during adulthood these patients often present with premature ovarian failure and infertility.

Gilles de la Tourette's syndrome (TS) is a well known syndrome [5] that has a typical onset in childhood, mostly between five and six years of age [6]. It is defined by the occurrence of multiple motor and one or more vocal tics; even if not concurrent, they should be present almost every day, usually in bouts, for no less than 12 months (a 'free period' of less than three months is accepted). Tics should begin before the age of 18 and should not be a consequence of a substance or of a general illness [7]. Diagnosis is usually delayed more than five years from the start of symptoms, often because patients and their families tend to hide the symptoms [8]. Frequently associated symptoms include coprolalia, obsessive-compulsive disorder (or obsessive traits), 
attention deficit (with or without hyperactivity), and anxiety disorders.

In the present work, we report the case of a girl with prenatal diagnosis of 47 (XXX) syndrome with mental retardation and symptoms of TS.

\section{Case presentation}

The parents of an 11-year-old Italian Caucasian girl requested she be evaluated for a suspected anxiety disorder. Our patient had been found to have 47(XXX) syndrome after a prenatal investigation (amniocentesis due to the relatively high maternal age). She was born full term after a normal pregnancy; no problems were reported during the perinatal or the neonatal period. Her parents described her psychomotor development as normal. She went to kindergarten by the age of three without any significant difficulty. She attended primary school with no apparent problems for the first four years, and then learning difficulties increasingly began to be reported. Her parents also referred to a significant difficulty in making and maintaining friends. They suspected she may have a specific learning disorder, since a cousin of our patient was dyslexic.

When we first saw her she was attending the first year of the 'scuola secondaria di primo grado' (VIth grade); her parents described mainly difficulties in writing, a high level of performance anxiety and lack of self-confidence. They also mentioned the occurrence of occasional tic bouts, which they considered as a manifestation of anxiety.

She seemed at first to be scared by the clinical examination, and she felt embarrassed by her appearance, although she had no dysmorphic features and her auxologic parameters were in the normal ranges (height: 75th percentile, weight: 50th percentile). Results of her general physical examination were normal, with the exception of a partial dental malposition and signs of nail biting. Her neurological examination was almost normal as well, but multiple motor tics (simple and complex) involving her head, arms and mouth, and vocal tics, were evident. They tended to become almost continuous when she was asked to perform quick calculations or any other cognitive task subjectively considered difficult.

Although our patient considered tics to be 'not important' and refused to list involuntary movements she experienced, she admitted that they were 'annoying' in social situations. During the evaluation, the following tics were seen: eye blinking (both unilateral and bilateral), grimacing of the mouth, throwing back of the head, quick flexions or extension of one or both arms, knuckle popping, throat clearing, sniffling, and coughing. Most motor tics were partially masked by added voluntary movements to resemble 'normal', although always not fully appropriate, activities.

To better understand the reasons leading to her academic difficulties, a neuropsychological evaluation was proposed. She was very shy with therapists and doctors of either sex; her lack of self-confidence was evident and manifested as requests for supplementary explanations about the cognitive tasks she was asked to perform. The number of tics was noted to increase during evaluation, especially when she needed to find or adapt cognitive strategies on her own to successfully complete tasks. Details of the neuropsychological evaluation are given in Table 1; the tests are among those routinely used in Italy and recommended by the Italian Society of Child and Adolescent Neuropsychiatry (SINPIA). Spontaneous writing was not adequate for her school level in terms of orthography or in terms of text structure.

In short, our patient showed a mild mental retardation with a relatively higher performance level. Minor difficulties in reading and writing were noted, and her reading comprehension was below average. Her mathematical abilities were severely compromised.

Our patient showed an important deficit of planning strategies, including the visual-constructional praxis, visuomotor integration and short-term spatial memory. The tendency to act without considering rules (shown by her performance in the Tower of London test) can be read as an alteration in inhibitory function, which is a rather typical feature of TS [9]. Impairment in visual working memory tasks has been reported in patients with TS as well, but our findings do not allow us to exclude the effect of comorbidities [9].

\section{Discussion}

A cognitive behavioral treatment was proposed (Habit Reversal Therapy [10]), but her parents refused consent to any intervention aimed at reducing her tics saying that 'they were not important'. Given their definite position, no pharmacological therapy was considered even if the high levels of anxiety shown by our patient would have required treatment. They accepted only an aide in order to allow their daughter to continue going to school (no differential classes exist in Italy; children with significant neuropsychiatric problems producing a condition of disability attend normal schools with a teacher and sometimes an educator to individually support them).

Our patient showed symptoms that can be produced independently by her chromosomal abnormality and by TS; namely, she has a significant impairment in the domain of executive functions (EFs). These can be defined as a group of neuropsychological abilities including action starting and control, flexibility, goal 
Table 1 Neuropsychological profile of our patient

\begin{tabular}{|c|c|}
\hline Test/factor & Score/rating \\
\hline \multicolumn{2}{|l|}{ WISC III: } \\
\hline Total IQ & 55 \\
\hline Verbal IQ & 51 \\
\hline Performance IQ & 70 \\
\hline Edinburgh Handedness Inventory & 24/24 (right lateralization) \\
\hline \multicolumn{2}{|l|}{ Constructional praxis } \\
\hline Blockbuilding models & 6/8 (slightly below average) \\
\hline Borrelly-Oleron & 3/8 (below average) \\
\hline \multicolumn{2}{|l|}{ Modified Frostig's test } \\
\hline QPVG & 8th percentile \\
\hline QPVMR & 6th percentile \\
\hline QIVM & 13th percentile \\
\hline \multicolumn{2}{|l|}{ Memory } \\
\hline Digit span & Normal \\
\hline Verbal span & Normal \\
\hline Corsi Block Tapping Test & Z-score of -3 \\
\hline \multicolumn{2}{|l|}{ Tower of London (executive functions) } \\
\hline Score & 10th to 15 th percentile \\
\hline Decision time & Z-score of -0.5 \\
\hline Executing time & Z-score of -0.55 \\
\hline Total time & Z-score of -0.67 \\
\hline Violation of rules & 6 (high) \\
\hline \multicolumn{2}{|l|}{ Modified Bells' Cancellation Test } \\
\hline Rapidity & 25th to 50th percentile \\
\hline Accuracy & 25th percentile \\
\hline \multicolumn{2}{|l|}{ Word reading } \\
\hline Time & Z-score of -0.86 \\
\hline Correctness & 15th percentile \\
\hline \multicolumn{2}{|l|}{ Non-word reading } \\
\hline Time & Z-score of -0.40 \\
\hline Correctness & $>15$ th percentile \\
\hline \multicolumn{2}{|l|}{ Text reading: rapidity/correctness } \\
\hline Rapidity & Z-score of - 1.6 \\
\hline Correctness & 8 errors (average) \\
\hline \multicolumn{2}{|l|}{ Text reading: comprehension } \\
\hline Narrative text & 7 correct answers out of 15 (below average) \\
\hline Informative text & 4 correct answers out of 15 (below average) \\
\hline \multicolumn{2}{|l|}{ Writing } \\
\hline List of words & 15th percentile \\
\hline List of non-words & 10th percentile \\
\hline Sentences (homophonic not homographs) & 15th percentile \\
\hline Dictation & 60th percentile (slightly below average) \\
\hline \multicolumn{2}{|l|}{ Mathematic abilities } \\
\hline Numbers and calculation quotient & $<50$ (very poor) \\
\hline Numbers quotient & $<50$ (very poor) \\
\hline Calculation quotient & $<50$ (very poor) \\
\hline
\end{tabular}

WISC III = Wechsler Intelligence Scale for Children III.

$\mathrm{IQ}=$ Intelligence Quotient.

QPVG = General Visuo-Perceptive Quotient.

QPVMR = Reduced Motricity Visuo-Perceptive Quotient.

QIVM = Visuo-Motor Integration Quotient. 
maintenance, and action planning [11]. They are thought to be important in those situations that involve planning, decision-making, error correction, and troubleshooting. They are also involved in the following scenarios: (a) unfamiliar situations, that is, where responses are not well learnt or contain novel sequences of actions; (b) dangerous or technically difficult situations; and (c) situations that require the overcoming of a strong habitual response or resisting temptation.

The frontal lobes are strongly involved in EFs [12] and a role for neural circuits involving the frontal lobes and EFs has also been advocated in TS [13]. A recent paper suggested that patients with TS exhibit significantly poorer performances in theory of mind (ToM) tasks: these tasks imply the ability to reason about mental states with a strong involvement of the frontal lobes. In patients with TS, ToM skills are thought to be reduced by a dysfunction in frontostriatal pathways involving ventromedial prefrontal cortex [14].

From a clinical and neuropsychological perspective, it is however hard to differentiate the specific contributions of the two disorders to our patient's impairment. Inhibition deficits are associated both with TS and with anxiety and with some forms of mental retardation; her verbal skills were reduced as expected in $47(\mathrm{XXX})$ syndrome, a fact that could have masked the reported deficit in verbal fluency tasks [14]. While the finding of a significant reduction of visuospatial memory (Corsi block-tapping test) is in line with reported deficits in visual or spatial working memory tasks [9], the finding of a normal verbal short-term memory seems to confirm that patients with TS do not show deficits in this subtype of working memory [15].

Another feature which is reported both in 47(XXX) syndrome and as a comorbidity of TS is anxiety; however, our patient showed a pattern of social anxiety which is thought to be typical of 47 (XXX) syndrome, that is, her anxious reactions were triggered by social stimuli such as the need to meet new people [4].

Treatment for a patient with both these conditions can be challenging: behavioral interventions have usually only been applied to patients with a normal or near-normal IQ, as they require the patient to understand and apply strategies in order to reduce the frequency and duration of tic bouts. Moreover, the typical 'stickiness' of thought processes in individuals with mental retardation can reduce the efficacy of psychological interventions [16]. However, most drugs used to reduce the severity of tics have been poorly tested or are not recommended in patients with mental retardation (as they can worsen cognitive performance) [10].

The phenotypic expression of $47(\mathrm{XXX})$ syndrome in our patient could be described as 'intermediate': she did not present with malformative signs but had mental retardation (with the typical pattern of a significantly lower verbal IQ).

In summary, this case report shows a typical example of denial of the importance of a symptom (tic bouts) that was a source of impairment for our patient, together with her social anxiety, dismissed as 'not important' by the parents and by the girl herself. This lack of consciousness of the importance of a medical condition or of a symptom is a factor commonly seen in parents refusing rehabilitative treatment [17].

\section{Conclusions}

To the best of our knowledge, this is the first report of a patient with 47 (XXX) syndrome and TS. Although this kind of association is probably rare, a thoroughly evaluation of these patients could be of help in improving our understanding of these disorders but also in planning better tailored therapies and/or rehabilitative treatments. This is especially important because these patients are likely to experience the difficulties described in patients with either isolated 47(XXX) syndrome [4] and in those with isolated TS [18] in real-life situations.

\section{Consent}

Written informed consent was obtained from the patient's next-of-kin for publication of this case report. A copy of the written consent is available for review by the Editor-in-Chief of this journal.

\section{Authors' contributions}

$M C$ and MC performed neuropsychiatric and general medical evaluation of our patient. SDV, RD and SDL performed the neuropsychological evaluation of our patient. All authors contributed to writing the manuscript, which they all read and approved in its final version.

\section{Competing interests}

The authors declare that they have no competing interests.

Received: 31 August 2011 Accepted: 5 November 2011

Published: 5 November 2011

\section{References}

1. Jacobs PA, Baikie AG, Brown WM, Macgregor TN, Maclean N, Harnden DG: Evidence for the existence of the human "super female". Lancet 1959, 2:423-425

2. Ben Hamouda $H$, Mkacher $N$, Elghezal H, Bannour $H$, Kamoun M, Soua $H$, Saad A, Souissi MM, Sfar MT: Prenatal diagnosis and prognosis of triple $X$ syndrome: 47, XXX. J Gynecol Obstet Biol Reprod (Paris) 2009, 38:599-603.

3. Lalatta F, Quagliarini D, Folliero E, Cavallari U, Gentilin B, Castorina P, Forzano F, Forzano S, Grosso E, Viassolo V, Naretto VG, Gattone S, Ceriani F, Faravelli F, Gargantini L: Triple X syndrome: characteristics of 42 Italian girls and parental emotional response to prenatal diagnosis. Eur J Pediatr 2010, 169:1255-1261.

4. Otter M, Schrander-Stumpel CT, Curfs LM: Triple X syndrome: a review of the literature. Eur J Hum Genet 2010, 18:265-271.

5. Gilles de la Tourette G: Etude sur une affection nerveuse caracterisee par de l'incoordination motrice accompagnee d'echolalie et de coprolalie. Arch Neurol 1885, 9:19-42, 158-200.

6. Neuner I, Ludolph A: Tics and Tourette's syndrome throughout the life span. Nervenarzt 2009, 80:1377-1387. 
7. American Psychiatric Association: Diagnostic and Statistical Manual of Mental Disorders. 4 edition. Washington DC: APA; 2000, text revision.

8. Arana-Lechuga Y, Sanchez-Escandon O, de Santiago-Trevino N, CastilloMontoya C, Teran-Perez G, Velazquez-Moctezuma J: Risperidone treatment of sleep disturbances in Tourette's syndrome. J Neuropsychiatry Clin Neurosci 2008, 2:375-376.

9. Eddy CM, Rizzo R, Cavanna AE: Neuropsychological aspects of Tourette syndrome: a review. J Psychosom Res 2009, 67:503-513.

10. Verdellen C, van de Griendt J, Hartmann A, Murphy T, ESSTS Guidelines Group: European clinical guidelines for Tourette syndrome and other tic disorders. Part III: behavioural and psychosocial interventions. Eur Child Adolesc Psychiatry 2011, 20:197-207.

11. Stuss DT, Knight RT, (eds): Principles of Frontal Lobe Function Oxford, UK: Oxford University Press; 2002.

12. Shallice T, Burgess PW: Deficits in strategy application following frontal lobe damage in man. Brain 1991, 114:727-741.

13. Papazian O, Alfonso I, Luzondo RJ: Executive function disorders. Rev Neurol 2006, 42(Suppl 3):S45-S50.

14. Eddy CM, Mitchell IJ, Beck SR, Cavanna AE, Rickards H: Social reasoning in Tourette syndrome. Cogn Neuropsychiatry 2011, 16:326-347.

15. Eddy CM, Mitchel IJ, Beck SR, Cavanna AE, Rickards H: Altered attribution of intention in Tourette syndrome. J Neuropsychiatry Clin Neurosci 2010, 22:348-351.

16. Roessner V, Plessen KJ, Rothenberger A, Ludolph AG, Rizzo R, Skov L, Strand G, Stern JS, Termine C, Hoekstra PJ, ESSTS Guidelines Group: European clinical guidelines for Tourette syndrome and other tic disorders. Part II: pharmacological treatment. Eur Child Adolesc Psychiatry 2011, 20:173-196.

17. Chiappedi M, Maltagliati S, Amoruso A, Dolci R, Carniglia C, Bejor M: Child rehabilitation refusal: why it happens and possible strategies to avoid it. Eur J Phys Rehabil Med 2009, 45:487-492.

18. Channon S, Crawford S, Vakili K, Robertson MM: Real-life-type problem solving in Tourette syndrome. Cog Behav Neurol 2003, 16:3-15.

doi:10.1186/1752-1947-5-542

Cite this article as: Chiappedi et al:: Gilles de la Tourette's syndrome in a patient with $47(\mathrm{XXX)}$ syndrome: a case report. Journal of Medical Case Reports 2011 5:542.

\section{Submit your next manuscript to BioMed Central and take full advantage of:}

- Convenient online submission

- Thorough peer review

- No space constraints or color figure charges

- Immediate publication on acceptance

- Inclusion in PubMed, CAS, Scopus and Google Scholar

- Research which is freely available for redistribution

Submit your manuscript at www.biomedcentral.com/submit 